\title{
Educating globally for health
}

The theme for this issue is health-related education, and the editors are pleased at the numbers of submissions and the enthusiasm for this topic. Clearly there are efforts on a broad front to relate Christian understanding to education with a global health perspective. Here is a survey of what you will find in this issue. Additionally, several more articles to supplement this theme are being considered for publication in the near future.

Huw Morgan and Sharon Falkenheimer describe the efforts of PRIME, a UK-based Christian medical education charity, to restore a Christian moral and spiritual character to healthcare globally. Helen Wordsworth describes the development of parish nursing in the UK, again an effort to restore a spiritual character to healthcare. Fountain, Mukooza, and Kanyesigye describe the establishment of an undergraduate university course in health and wholeness, now taken by more than 26,000 students in Uganda. The effectiveness of these efforts has not been directly measured, but in other areas assessments are ongoing. Michael Brooks and Maggie Ehrenfried report the development, implementation, and measurement of healthcare capacity and quality over nine quarters from 2012 to 2014 in Burundi using a horizontal franchise business model. This work is the brainchild of LifeNet International whose leadership is particularly strong in entrepreneurship, business management, and economics.

Thomas and Maliekal from the Catholic Health Association of India present a comprehensive approach to maternal child health based on human rights, and the impact of nun-nurses trained as locally active community health enablers for better maternal-child health. Butcher, et al.evaluate the effectiveness of a community health worker training course in India to build capacity for health promotion access in rural areas. Shumba, Miyonga, et al. present a well-done qualitative study on the cultural, economic, and social barriers to family planning in Uganda. These studies assess the effectiveness of very grass roots efforts in developing world contexts to build health capacity. Young, et al. use realist evaluation to study the formation and function of Disabled Peoples' Groups in North India. Slashcheva, et al. give a description and growth analysis of the yearly conferences sponsored by the US-based Christian Medical and Dental Associations for missionary doctors and staff. Deborah Kroeker and Anne Walling describe an analysis of the effectiveness of a Medical Education International conference in Mongolia. Kathryn Butler gives a moving personal account of how in the midst of the frustrations of inadequate resources, practicing loving presence, and learning from the afflicted is what God desires beyond technical health care provision.

This issue has four reports from a preconference held in November 2015, immediately prior to that year's Global Missions Health Conference in Louisville, Kentucky, USA. These are mentioned separately along with commentary by the editors with guest Vinod Shah on the sometimes understated challenges of learning/ teaching methods, paternalism, and corruption in health-related education.

The commentary by Jose Miguel DeAngulo and Luz Stella Losada deserves special mention. This article follows an earlier review "Health Paradigm Shifts in the $20^{\text {th }}$ Century" in Vol 2 Issue 1 of the journal by the same authors that lays out the evolution of the paradigms by which we have come to our current framework for understanding health care provision and prevention. In this issue, they explain how new findings in the neuroscience of the developing infant may provide the grounds for an entirely 
new framework for understanding global health priorities. There have indeed been astounding advances in knowing how the brain works and, especially, the amazing amount of plasticity and interplay with the environment. Because of similarities between these new findings and the earlier paradigm involving the social determinants of health, neither editors nor reviewers were convinced that an entirely new paradigm was indicated. However, given the evidence of the high impact and cost-effectiveness of interventions during the formative first 1000 days of life, this perspective requires emphasis for our future in transformative global health and sustainable development. 